\title{
Behavioural Issues Causative to Corruption
}

\author{
Rumaizah Mohd Nordin, Roshana Takim, \\ Abdul Hadi Nawawi
}

\author{
Faculty of Architecture, Planning \& Surveying, \\ Universiti Teknologi MARA, Malaysia \\ rumaizah.mnordin@gmail.com
}

\begin{abstract}
Construction industry is fragmented, involves various stakeholders with a complex contractual structure, and variety of psychological human behaviours that expose to corrupt activities. Corruption is a deviant behaviour which deviates from normal duties of a public role, pecuniary, and violates official ethics of public services. The objective of this paper is to investigate the behavioural factors that lead to corruption in construction based on the 'Model of Corrupt Action'. Three methods of data collections (i.e., interviews, workshop and questionnaire) are employed to derive to the solutions. The results showed that 'desire' and 'intentions' are the significant behavioural factors to corrupt actions.

Keywords: Behaviour, corruption, construction environment

eISSN 2398-4295 @ 2018. The Authors. Published for AMER ABRA cE-Bs by e-International Publishing House, Ltd., UK. This is an open-access article under the CC BY-NC-ND license (http:///creativecommons.org/licenses/bync-nd/4.0). Peer-review under responsibility of AMER (Association of Malaysian Environment-Behaviour Researchers), ABRA (Association of Behavioural Researchers on Asians) and CE-Bs (Centre for EnvironmentBehaviour Studies), Faculty of Architecture, Planning \& Surveying, Universiti Teknologi MARA, Malaysia.
\end{abstract}

DOI: http://dx.doi.org/10.21834/ajbes.v3i11.96 


\subsection{Introduction}

The construction industry is a major contributor to the overall economic growth (Abdullah et al, 2004). The construction process requires the contribution of many different stakeholders, involves various processes, different phases of work, and a great deal of inputs from both the public and private sectors (Abdul-Aziz \& Mohmad, 2010). One of the most challenges facing the industry is notoriety for corruption (Jong et al, 2009). Construction is prone to corruption since it is fragmented, involves a large number of participants in a complex contractual structure that leads to a variety of psychological human behaviour and attitude inclining towards corrupt activities (Stansbury, 2005; Mohd-Nordin et al, 2012). Corrupt practices can be found in every phase of construction projects that leads to devastating consequences on the quality of the built environment, project delivery period, and competitive performance of the industry (Sohail \& Cavill, 2006; Murray \& Meghji, 2009). Corruption is a deviant behaviour which deviates from normal duties of a public role, pecuniary or status gain, and violates official ethics of public services due to private-regarding influences (Nye, 1967; Park \& Blenkinsopp, 2011). It is a complex set of personal enrichment processes involving many types of crime that imply some form of illicit human behaviours which are difficult to recognise or measure (Neelankavil, 2002; Otusanya, 2011). Corrupt activities derive from environmental factors notably due to distorted or opaque government behaviour and decisions, weak counter-corruption institutions, cultures that intertwined gift-giving with bribery, poor quality of public service and inadequate openness in trade and market access (Luo, 2004). A great deal of effort has been done to fight corruption in order to turn the industry towards prosperity with greater equity and give life to sustainable development. Thus, the objective of this paper is to investigate the behavioural factors that lead to corruption in construction based on the 'Model of Corrupt Action'.

\subsection{Corruption in Construction and Human Behaviour}

According to Laland \& Brown (2011), human behaviour is largely learned from other people and primarily influenced by culture. Eshliki \& Kaboudi (2012) put forward factors influencing perception and attitude, and nature and extent of the impact of certain behaviour are likely to be different in each community. It is broadly understood that there are many antecedents of behaviour, including immediate environmental or institutional constraints and cultural values. In the study of corruption, cultural values are important because it influence decisions whether to engage in the corrupt transaction. Moreover, the environment that tolerated corruption in a way forced individual to pay bribes, under-counter gifts, dishonest dealings to do construction businesses (Getz \& Volkema, 2001). Corruption is blamed to represent a threat to construction and engineering companies, as well as those institutions companies that finance, guarantee or insured construction projects. Corruption in construction could result in wasted tender expenses, tendering uncertainty, increased project costs, economic damage, blackmail, criminal prosecutions, fines, blacklisting, and reputational risk (Stansbury, 2005). In this regard, more importantly, corruption in construction should be treated based on the behavioural factors (Gebel, 2012) apart from the technical domain. This is due to the fact that corruption occurs as a form of behaviour violating the official ethics of 
public services, a stem of social norms that emphasise gift-giving and loyalty to family or clan, rather than the rule of laws (Park and Blenkinsopp, 2011).

Figure 1(a) shows the development of Model of Corrupt action while Figure 1(b) introduces a Model of Corrupt Action. The model examines the person-based determinants of human behaviour in interaction with a specific situational context (Rabl \& Kuhlmann, 2008). This model is developed based on Model of Effortful Decision Making and Enactment (MEDME) by Bagozzi et al (2003) that integrates Rubicon Model of Action Phases (RMAP) (Gollwitzer, 1990) and Theory of Planned Behaviour (TPB) (Ajzen, 1991) as shown in figure 1(a). Based on the ideas of Gollwitzer (1990), Ajzen (1991) and Bagozzi et al (2003) provide an input to the full Model of Corrupt Action by Rabl and Kuhlmann (2008).

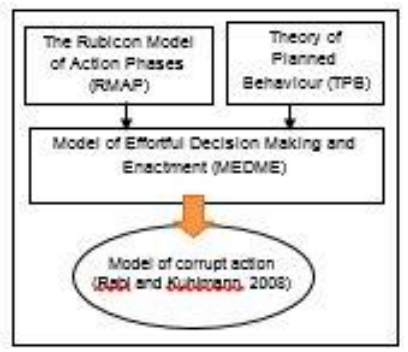

Figure 1(a): The development of Model of Corrupt Action

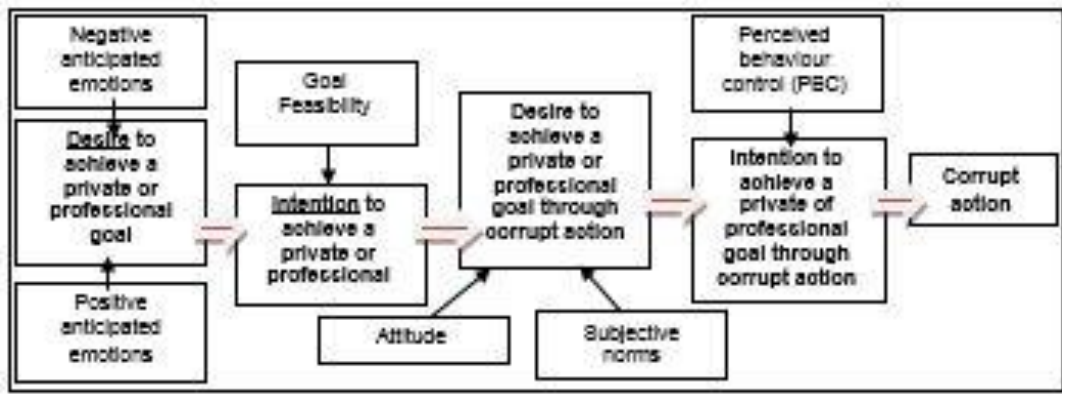

Figure 1(b): The Model of Corrupt Action

(Source: Rabl and Kuhlmann, 2008)

The Model of Corrupt Action consists of two main factors the 'desire' and 'intention' to achieve through corrupt actions. According to the model, the desire to achieve a private or professional goal depends on the positive and negative emotions anticipated with regard to goal attainment. These emotions have motivating power and trigger decisions as part of a general process of self-regulation. The desire to achieve the private or professional goal has to be transformed into an intention since desires are necessary antecedents to intention. In 
order to achieve the goal, people tend to consider the difficulties or opportunities available. The lower the goal feasibility the higher the strength of intention will be. The desirability of corrupt action as a way to achieve the private or professional goal is caused by goal intention. For the non-routine goal, the goal intention and implementation intention are based on deliberative process considering the desirability and feasibility of achieving the goal. Whether the implementation intentions are actually formed depends on the anticipation of difficulties which is termed as perceived behaviour control (PBC). PBC is assumed to reflect past experiences and anticipated impediments and obstacle. Hence, the stronger an individual's intention to perform the particular behaviour the greater will be the outcomes of PBC. Finally, whether the intention is transformed into action is depending on the volitional strength. The stronger the person is committed to a certain way of achieving a goal, the more likely the relevant actions are actually initiated (Gollwitzer, 1990). Since, there has been little research focussing on the person who acts corruptly, the significant of this study is to investigate how behavioural factors leading to corrupt action by utilising the Model of Corrupt Action.

\subsection{Methodology}

A mixed method incorporating qualitative and quantitative approaches was taken to conduct this study through exploratory interviews, a brain-storming workshop and questionnaire survey as the means of data collection. Figure 2 summarises the data collection methods (Data 1, 2, 3) and respondents for each data collection.

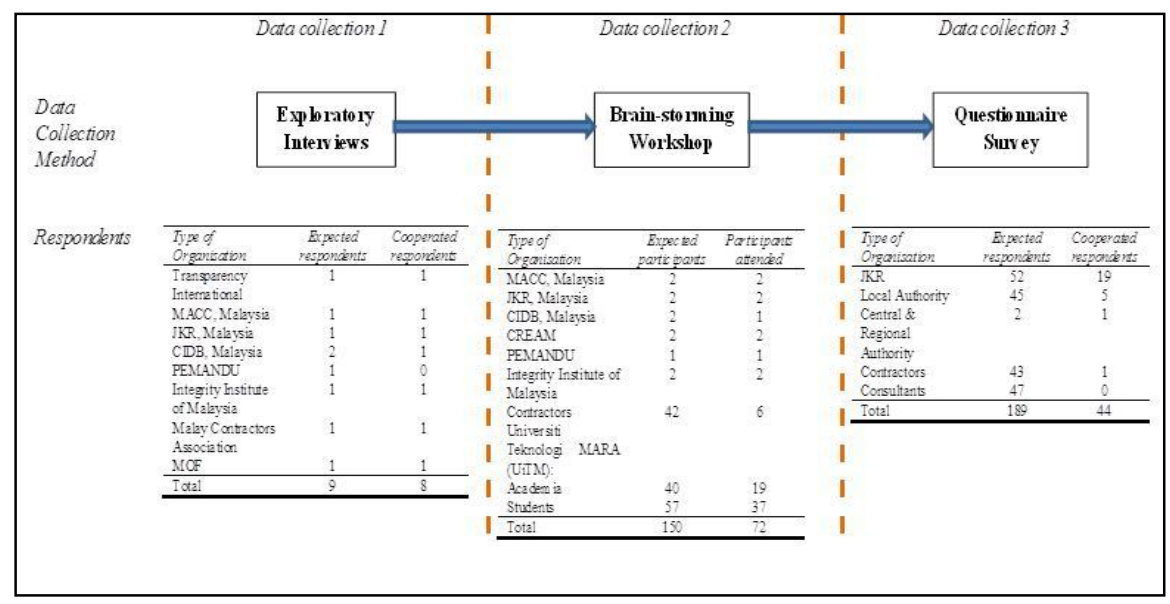

Figure 2: Data collection methods and respondents

The first method was the face-to-face exploratory interviews which were designed to gather preliminary data on corruption in Malaysia, particularly in the construction industry. A response rate of $88.89 \%$ achieved was overwhelming. The second method is through a brain- 
storming workshop conducted on the 27th March 2012 to extract initial view and ideas from the experts and experienced practitioner in the Malaysian construction industry. Two prominent keynotes speakers were engaged to provide overviews on the transparency issues (TI) in construction (i.e., Corruption Prevention in Construction Sector by Deputy Chief Commissioner Malaysian Anti-Corruption Commission (MACC) Malaysia, and Integrity in Construction by Senior Assistant Director, Inspectorate and Integrity Department, Public Work Department (PWD) Malaysia). A total of $48 \%$ of response rate were obtained for the workshop from various government agencies, contractors, academia and post-graduate students. The outcomes for both exploratory interviews and the brain-storming workshop were processed by content analysis techniques.

In order to reinforce the results obtained, a third data collection method utilised a questionnaire survey was conducted based on the nine behavioural factors of Model of Corrupt Action (See Table 3). To measure these factors, a-ten-points Likert-type scaled items were deployed for the participants to indicate their level of agreement and disagreement. A non-probability of judgement purposive sampling was used based on the expertise of respondents (Government, public authorities, consultants and contractors) on the subject matters. A total response of $23.28 \%$ was attained. The response rates for the three data collection methods (88.89\%; $48 \%$ and $23.28 \%$ ) are acceptable since the normal response rate in the construction environment is around 20 to 30 percent (Takim et al., 2004). Based on the designation and professional background of the participants, it is reasonable to infer that the majority of the participants have sound knowledge on the issues of corruption in construction.

\subsection{Results and Discussions}

\section{Findings from Exploratory Interview (Data collection 1)}

Table 1 shows the results of the exploratory interviews. It can be deduced that 100 percent of the respondents agreed that corruption is very much related to human behaviours. It includes from an obedient behaviour of individual to follow the law; behaviour that did not see corruption as a crime; and negative behaviours of greed, jealousy, boast and dishonest. However, three out of eight respondents highlighted that even though with various measures in combating corruption, human behaviour will affect the decision made by the individual whether to commit to corrupt activity or otherwise. According to Bagozzi et al, (2003), the behavioural decision making is the goal intention that formed as a result of the deliberating process for desirability and feasibility. Adding to that, desire is a state of mind whereby an individual has a personal motivation to perform an action or to achieve a goal while, feasibility is the ease or difficulty of attaining the end-state (Perugini \& Bagozzi, 2004; Bagozzi et al, 2003). Hence, individual behaviour is an important feature contribution to corrupt action derived by desire and feasibility. 
Table 1: Results from exploratory interviews

\begin{tabular}{|c|c|c|}
\hline Respondents & $\begin{array}{l}\text { Agree that } \\
\text { corruption is } \\
\text { due to human } \\
\text { behaviour }\end{array}$ & Comments \\
\hline El1 & $\sqrt{ }$ & $\begin{array}{l}\text { It is essential to create a society which has rule of laws, the people } \\
\text { following the laws and good governance. }\end{array}$ \\
\hline El2 & $\sqrt{ }$ & $\begin{array}{l}\text { Our culture permits it (corruption) to happen because we did not see } \\
\text { corruption as a crime or sin such as gambling or infidelity. }\end{array}$ \\
\hline El3 & $\sqrt{ }$ & Sometimes they have no choice. They have to do it. \\
\hline El4 & $\sqrt{ }$ & $\begin{array}{l}\text { Corruption lies in our culture due to behaviour of greed, jealousy and boast } \\
\text { of individuals. }\end{array}$ \\
\hline El5 & $\sqrt{ }$ & $\begin{array}{l}\text { Anything that will de-value the trust, provide a corruptive elements in it } \\
\text { since trust means believe and honesty. }\end{array}$ \\
\hline El6 & $\sqrt{ }$ & $\begin{array}{l}\text { Many laws and regulations have put in place to fight corruption, but again it } \\
\text { depends on the individual behaviour to execute. } \\
\text { However, Individuals who have wisdom will also have indemnity of soul of } \\
\text { God that will guarantee them for self-regulated as a control. }\end{array}$ \\
\hline El7 & $\sqrt{ }$ & $\begin{array}{l}\text { You can have all sorts of plans and systems to fight corruption, but these } \\
\text { corruptors are advance in their ways to corrupt. As such it depends on the } \\
\text { individual whether to be a corrupt person or otherwise. }\end{array}$ \\
\hline El8 & $\sqrt{ }$ & Corruption includes cheating and dishonest. \\
\hline
\end{tabular}

\section{Findings from Brain-Storming Workshop (Data collection 2)}

Table 2 shows the results of the brain storming workshop which discussed on behavioural issues in the development of construction projects with regards to corruption.

Table 2: Results from the brain storming workshop

\begin{tabular}{lll}
\hline & Group 1 \\
& (Behaviour) \\
\hline & $\bullet$ & Mentality -lack of individual integrity \\
Sources of corruption & $\bullet$ & Culture \\
& $\bullet$ & Environment \\
& $\bullet$ & Lifestyle \\
& $\bullet$ & Inevitability \\
\hline
\end{tabular}

The results indicated that sources of corruption consist of five elements: mentality, culture, environment, lifestyle, and inevitability. Mentality means mental capacity or intelligence possess by an individual (Merriam-Webster, 2012). Other definitions of mentality intelligence include adaptability to a new environment or to changes in the current environment, the ability to evaluate and judge, the ability to comprehend complex ideas, the capacity for original and productive thought, the ability to learn quickly and learn from experience and even the ability to comprehend relationships. For this context, mentality is referred to the lack of individual integrity that leads to negative behaviour. Culture, on the other hand, is a cohesive set of ideas, belief and knowledge that have been the primary influence on human behaviour to engage in corrupt transactions or otherwise (Laland and Brown, 2011; Getz and Volkema, 2001). According to Andrei et al. (2009), cultural factors 
have a strong impact on the level of corruption and enabling its transmission throughout the system. It is more saddening when corruption as payments to public agents for private benefit in the form of 'gifts' are not viewed as corruption (McChesney, 2010).

In addition, the environment that inclined to corruption could force individual to pay bribe. For instance, based on Getz and Volkema (2001), it is impossible to do construction business in a certain part of the world without paying bribes. The discussion also highlighted that the current lifestyle of the community for a high standard of living contributed to corruption. To a certain extent, due to the influence of luxurious lifestyle, public officials in the construction organisations tend to use their discretionary power for their private satisfaction (Aidt, 2011). In terms of inevitability, corruption is thought by many to be unavoidable in doing construction businesses (Getz and Volkema, 2001). As cited in Seleim and Bontis (2009), such situation tends to occur due to the opportunities of corrupt acts from the well-established norms, rules, policies and procedures of an institution or country. It resulted from individual perception claiming that in order to obtain projects, it is inevitable to be through informal channels (i.e., pay bribes, demand for bribes, and dishonest dealings).

\section{Findings from Questionnaire Survey (Data Collection 3)}

i) Reliability of Data

Table 3 shows the results for the reliability based on the Cronbach's Alpha (CA) value.

Table 3: Reliability of questionnaire survey

\begin{tabular}{llc}
\hline Behavioural factors & $\begin{array}{c}\text { Cronbach's } \\
\text { alpha }\end{array}$ & $\begin{array}{c}\text { No of } \\
\text { items }\end{array}$ \\
\hline 1. Desire to achieve a private or professional goal & 0.886 & 2 \\
2. Intention to achieve a private or professional goal & 0.651 & 3 \\
3. Goal feasibility & 0.781 & 2 \\
4. Desire to achieve a private or professional goal through corrupt action & 0.585 & 3 \\
5. Subjective norms & 0.622 & 3 \\
6. Intention to achieve a private or professional goal through corrupt action & 0.593 & 2 \\
7. Perceived behavioural control (PBC) & 0.691 & 3 \\
8. Attitude & 0.985 & 9 \\
9. Corrupt acts* & - & - \\
\hline ** The construct was measured by a single item & & \\
\hline
\end{tabular}

The reliability of the a-ten-points Likert-type scaled measure was determined by using CA coefficient on the samples. The calculation of CA is based on number of items and the average inter-item correlation. It ranges from ' 0 ' for a completely unreliable test to ' 1 ' for completely reliable test (Hinton et al, 2004). Pallant (2001) suggests the value of alpha should be greater than 0.7 for the scale to be reliable with the sample. Nunnally (1978) suggests that the modest reliability scale is in the range of $0.50-0.60$, while Hinton et al. (2004) and Takim (2004) consider moderately reliable scale in the range of $0.5-0.75$. The results 
presented show that the $\mathrm{CA}$ is in the range of $0.593-0.985$ showing that the data collected are interrelated and reliable.

\section{ii) Descriptive analysis}

Table 4 presents the descriptive analysis of this research. Close observation revealed that the 'desire to achieve a private or professional goal' (mean value $=5.90)$ ' correspond to the 'desire to achieve private or professional goals through corrupt action' (mean=4.28). Meanwhile, the mean value for the 'intention to achieve a private or professional goal' (mean value $=4.62$ ) matches the 'intention to achieve a private or professional goal through corrupt action' (mean value=4.13). The outcomes suggested that 'desires' and 'intentions' are the key words of behavioural factors responsible for corrupt actions. A desire is often classified as an emotion that induces consumers; while intention is the specific purpose of performing an action; the end or goal that is aimed at. In this case, both mean values of 'desires' are bigger compared to the values of 'intention' indicating that emotions are detrimental feature to sustainable development. Nevertheless, the intention to corrupt behaviour could be control if the actor has positive attitudes towards integrity.

Table 4: Descriptive statistics

\begin{tabular}{llc}
\hline Behavioural factors & Mean & SD \\
\hline 1. Desire to achieve a private or professional goal & 5.90 & 2.17 \\
\hline 2. Intention to achieve a private or professional goal & 4.62 & 1.82 \\
\hline 3. Goal feasibility & 5.90 & 2.10 \\
\hline 4. Desire to achieve a private or professional goal through corrupt action & 4.28 & 1.94 \\
\hline 5. Subjective norms (SN) & 2.88 & 1.87 \\
\hline 6. Intention to achieve a private or professional goal through corrupt action & 4.13 & 2.37 \\
7. Perceived behavioural control (PBC) & 3.12 & 1.74 \\
8. Attitude & 2.53 & 2.00 \\
9. Corrupt acts & 2.34 & 2.03 \\
\hline
\end{tabular}

Another factor that needs to be highlighted is 'perceived behavioural control' (PBC) with the mean value of 3.12. PBC it used in order to explain behaviour over which people have incomplete volitional control. For corrupt action, PBC can be due to the likelihood of detection and the extent of penalties. Ajzen (1991) emphasised that the stronger the individual intention to perform the behaviour under consideration, the greater the PBC. Finally, the mean value of 'corrupt acts' (mean value $=2.34$ ) appeared to be very small, which is contradicted to the mean value of 'intention to achieve a private or professional goal through corrupt action' (mean value=4.13). By and large, the stronger the intention to achieve private or personal goal through corrupt action, the more likely the corrupt action will be, which in this case is contradicted. The possible reason for this predicament could be due to respondents that deliberately fake the results in order to make them look good (Rees and Metcalfe, 2002). 


\section{iii) Non-parametric Spearman correlation}

A correlation is performed to test the degree to which the scores of the two variables corelates. According to Pallant (2011), correlation provides an indication that there is a relationship between two variables, however, it did not indicate that one variable causes another. Spearman correlation is used to correlate ordinal data that is not normal distributed (Hinton et al, 2004). A strong correlation indicates that there is only a small amount of error and most of the points lie close to the regression line; whilst a weak correlation indicates that there is a lot of error and the points are more scattered. Cited in Pallant (2011) and Cohen (1988) suggested that small $r=.10$ to .29 , medium $r=.30$ to .49 , and large $r=.50$ to 1.0 .

Table 5 shows the results of the correlation among the behavioural factors. In this test, 7 out of the 9 variables correlated to 'corrupt acts' are subjected to further investigations. These are: goal feasibility (rho= 0.121 ); desire to achieve a private or professional goal through corrupt action (rho= 0.338 ); subjective norms $(\mathrm{SN})$ (rho=0.485); intention to achieve a private or professional goal through corrupt action $(r h o=0.231)$; perceived behavioural control $(\mathrm{PBC})$ (rho $=0.601)$; and attitude (rho $=0.528)$.

Table 5: Correlation between behavioural factors

\begin{tabular}{|c|c|c|c|c|c|c|c|}
\hline Behavioural factors & 1 & 2 & 3 & 4 & 5 & 6 & 7 \\
\hline \multirow{2}{*}{ 1. Goal feasibility (GF) } & & $0.305^{*}$ & $0.421^{* *}$ & $0.269^{*}$ & 0.077 & 0.071 & 0.121 \\
\hline & & 0.022 & 0.02 & 0.039 & 0.310 & 0.322 & 0.216 \\
\hline \multirow{2}{*}{$\begin{array}{l}\text { 2. Desire to achieve a private or } \\
\text { professional goal through } \\
\text { corrupt action }\end{array}$} & & & $0.330^{*}$ & 0.117 & $0.554^{\star \star}$ & $0.430^{* *}$ & $0.338^{*}$ \\
\hline & & & 0.014 & 0.225 & 0.000 & 0.002 & 0.012 \\
\hline \multirow[t]{2}{*}{ 3. Subjective norms (SN) } & & & & 0.244 & $0.439^{* \star}$ & $0.413^{* *}$ & $0.485^{* *}$ \\
\hline & & & & 0.055 & 0.001 & 0.003 & 0.000 \\
\hline \multirow{2}{*}{\multicolumn{2}{|c|}{$\begin{array}{l}\text { 4. Intention to achieve a private } \\
\text { or professional goal through } \\
\text { corrupt action }\end{array}$}} & & & & 0.199 & 0.178 & 0.231 \\
\hline & & & & & 0.097 & 0.124 & 0.066 \\
\hline \multicolumn{2}{|l|}{$\begin{array}{l}\text { 5. Perceived behavioural control } \\
\text { (PBC) }\end{array}$} & & & & & $\begin{array}{l}0.447^{* *} \\
0.001\end{array}$ & $\begin{array}{l}0.601^{* *} \\
0.000\end{array}$ \\
\hline 6. Attitude & & & & & & & $\begin{array}{l}0.528^{\star \star} \\
0.000\end{array}$ \\
\hline
\end{tabular}

7. Corrupt acts

The results indicated that medium correlation occurred between 'desires to achieve a private or professional goal through corrupt action' and 'corrupt acts' with rho value of 0.338 . According to Bagozzi et al. (2003), implementation desires are caused by goal intention. If there is a high intention to realise the private or professional goal, it can be assumed that this may result in a certain desirability of corrupt action. The next factor is goal feasibility (GF). According to Gollwitzer (1990), GF is the ability to achieve the goal whether necessary opportunities available and the situational context is facilitating or impeding. Despite GF is not correlated directly to 'corrupt acts', GF has a medium positive correlation with 'desire to achieve a private or professional goal through corrupt action'. This implies that the more feasible the targeted goal is the stronger people desire to achieve it.

Furthermore, a subjective norm (SN) refers to the perceived social pressure to perform or 
not the said behaviour, whilst attitude refers to the degree to which a person has favourable or unfavourable evaluations of the behaviour under consideration (Ajzen, 1991). According to the Theory of Planned Behaviour (TPB), the stronger an individual's intentions to perform the behaviour under consideration are the more favourable attitude and SN with respect to the behaviour. Conversely, Bagozzi et al. (2003) argue that attitude and SN influence intention to the extent that they merely lead to a desire to act. Bagozzi et al. (2003) arguments could be the possible reasons that showed attitude, SN and desire to achieve a private or professional goal through corrupt action correlated with corrupt acts. Expectedly, the result of this study is consistent with Powpaka's (2002) findings indicated that attitude had the strongest impact on desire to bribe.

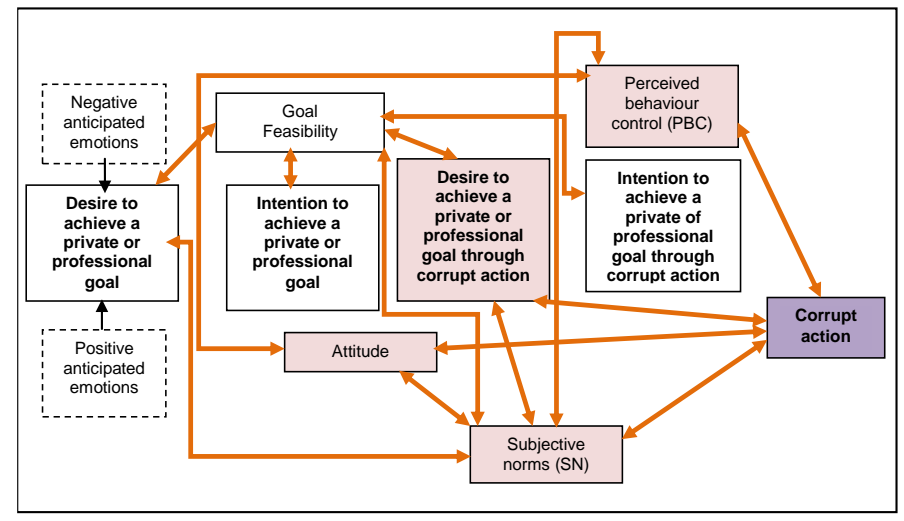

Figure 3: Correlation between variables

On the other hand, PBC is referred to perceived ease or difficulty of performing the behaviour (Ajzen, 1991). The results showed that there is a strong positive correlation between PBC and corrupt acts with rho value of 0.601 which is in line with (Rabl \& Kuhlmann, 2008). This showed that a higher PBC may increase the likelihood of corrupt acts. Despite the 'intention to achieve a private or professional goal through corrupt action' is a strong predictor for corrupt acts as mentioned by Rabl and Khulmann, (2008), unfortunately, the result (rho $=0.231$ ) shows that there is no correlation occurred between them. This may be due to the personality of the respondents that could fake their answer which is unethical (Rees and Metcalfe, 2003). The overall summary of the results is illustrated in figure 3 below.

\subsection{Conclusion}

This paper has presented the findings on the behavioural factors that lead to corrupt action based on the Model of Corrupt Action by Rabl and Kuhlmann (2008). The results revealed that four significant factors (i.e., the desire to achieve a private or professional goal through corrupt action; subjective norms (SN); Perceived Behavioural Control (PBC) and attitude) are positively related to corrupt acts. Surprisingly, two factors (i.e., intention to achieve a private 
of professional goal through corrupt action and goal feasibility) do not correlate to corrupt acts. This implies that the power of 'desire' to corrupt acts is the dominant factor compared to 'intention'. Since desire depends on individual emotions, there is a tendency that particular emotions being 'fitting' or 'appropriate' for certain situation. Intentions, on the other hand, are mental states that represent an action that prefers to be realised based on proper deliberation of good means and moral will (Lumer, 2012). This proves that, even though desire will influence intention, to a certain extent the intention will reduce due to control factors such as motivations, laws, regulations and values of the individuals. Meanwhile, perceived behavioural control and attitudes are the two significant factors indicated bigger values ( 0.601 and 0.528 ) to corrupt acts. Behaviours and attitudes are part of social psychology that affected by culture and in line with the opinions of Toor and Ofori (2008). They emphasised that there is a need to promote a positive culture in the construction industry, to develop individuals who possess positive values, and to practice high level of moral and ethical standards in order to eliminate corruption in construction. Hence, the behavioural factors and attitude should be given higher attention since the two factors leads to corrupt acts. A final confirmatory interview will be further conducted to validate the above findings.

The research presented in this paper is part of an ongoing Ph.D. research study at the Faculty of Architecture, Planning and Surveying, UiTM to develop a framework of transparency initiative for public construction projects in Malaysian construction industry. The result of the study could provide an insight into Malaysian construction project environment and could offer a valuable guideline, in particular to respective industry players that are looking forward to a more transparent construction market.

\section{Acknowledgement}

The authors would like to acknowledge the contribution from the Ministry of Higher Learning Malaysia through supporting the research.

\section{References}

Abdul-Aziz, A.-R., \& Mohmad, M.-D. (2010). Project manager competencies in undertaking construction project. Seri Iskandar, Perak.

Abdullah, F., Chiet, C. V., Anuar, K., \& Shen, T. T. (2004). An Overview on the Growth and Development of the Malaysian Construction Industry. Workshop on Construction Contract Management. Universiti Teknologi Malaysia.

Aidt, T. S. (2011). The causes of corruption. CESifo DICE Reort 2/2011, pp. 15-19.

Ajzen, I. (1991). The Theory of Planned Behaviour. Organisational Behaviour and Human Decision Process, 179211.

Andrei, T., Matei, A., \& Rosca, I. G. (2009). The Corruption: And Economic and Social Analysis. Editura Economica.

Bagozzi, R. P., Dholakia, U., \& Basuroy, S. (2003). How Effortful Decision Get Enacted: The Motivating Role of Decision Processes, Desires and Anticipated Emotions. Joournal of Behavioural Decision Making, 273-295. 
Eshliki, S. A., \& Kaboudi, M. (2012). Perception of Community in Tourism Planning: Ramsar, Iran. Journal of ASIAN Behavioural Studies, 51-64.

Gebel, A. C. (2012). Human nature and morality in the anti corruption discourse of Transparency International. Public Administration and Development, 32, 109-128.

Getz, K. A., \& Volkema, J. R. (2001). Culture, Perceived Corruption, and Economics. Business Society, 7-30.

Gollwitzer, P. M. (1990). Action Phases and Mindsets. In E. T. Higgins, \& R. M. Sorrentino, Handbook of Motivation and Cognition: Foundations of social behaviour (Vol 2) (pp. 55-62). New York: The Guildford Press.

Hinton, P. R., Brownlow, C., McMurray, I., and Cozens, B. (2004). SPSS Explained. New York: Routledge.

Jong, M. d., Henry, W. P., \& Stansburry, N. (2009, July). Eliminating corruption in Our Engineering/Construction Industry. Leadership and Management in Engineering, pp. 105-111.

Laland, K. N., \& Brown, R. G. (2011). Sense and nonsense: Evolutionary Perspectives of Human Behaviour. USA: Oxford University Press.

Lumer, C. (2012). The volitive and executive fuction of intention. Philosophy Studies

Luo, Y. (2004). An Organisational Perspective of Corruption. Management and Organisation Review, 119-154.

McChesney, F. S. (2010). The economic analysis of corruption. In B. L. Benson, \& P. R. Zimmerman, Handbook in the economics of crimes (p. 218). UK: Edward Elgar Publishing.

Mohd-Nordin1, R., Takim, R., \& Nawawi, A.-H. (2012). Transparency Initiatives (TI) in Construction: The Social Psychology of Human Behaviours. ASEAN Conference on Environment-Behaviour Studies. Bangkok: Elsevier.

Murray, M., \& Meghji, M. R. (2009). Corruption within International Engineering-Construction Projects. Retrieved June 15, 2010, from http://217.197.210.21/resources/integrity/meghi_construction_oct08.pdf

Neelankavil, J. P. (2002). International Business Corruption: A Framework of Causes, Effects and Prescriptions. Hofstra. Retrieved February 28, 2011, from http://www.aueb.gr

Nye, J. (1967). Corruption and Political Development: A Cost-Benefit Analysis. American Political Science Review.

Otusanya, O. J. (2011). Corruption as an obstacle to developing countries: a review of literature. Journal of Money Laundering Control, 14(4), 387-422.

Pallant, J. (2001). SPSS Survival Manual: A step by step guide to data analysis using SPSS for windows (Version 10-11). Buckingham: Open University Press.

Park, H., \& Blenkinsopp, J. (2011). The roles of Transparency and Trust in the Relationship between Corruption and Citizen Satisfaction. International Review of Administrative Sciences, 77(2), 254-274.

Perugini, M., \& Bagozzi, R. (2004). The Disticntion between Desires and Intentions. European Journal os Social Psychology, 69-84.

Powpaka, S. (2002). Factors Affecting Managers' Decision to Bribe: An Empirical Investigation. Journal of Business Ethics, 227-246.

Rabl, T., \& Kuhlmann, T. M. (2008). Understanding corruption in organisations - Development and empirical assessment of an Action Model. Journal of Business Ethics, 477-495. 
Mohd. Nordin, R., et.al. / Asian Journal of Behavioural Studies (AjBeS), 3(11) May / Jun 2018 (p.1-13)

Rees, D. J. and Metcalfe, B. (2002). The faking of personality, questionnaire results: who's kidding whom? Journal of Managerial Psychology, 18(22), 156-165.

Saleim, A., \& Bontis, N. (2009). The relationship between culture and corruption: a cross-national study. Journal of Intelectual Capital, 10, 165-184.

Stansbury, N. (2005). Exposing the Foundations of Corruption in Construction. United Kingdom: Transparency International.

Takim, R., Akintoye, A., \& Kelly, J. (2004). The Management og Stakeholders' Need and Expectations in the Development of Construction Projects in Malaysia. 4th International Postgraduate Research Conference (pp. 734744). United Kingdon: University of Salford.

Toor, S. \& Ofori, G. (2008), Leadership for Future Construction Industry: Agenda for Authentic Leadership. International Journal of Project Management, Volume 26, pp. 620-630. 